\section{START INS NEUE JAHR}

\author{
Von Studierenden im Stupa-- Seit der FVDZ-Hauptver- \\ sammlung organisieren sich, in enger Zusammenarbeit mit \\ dem Bundesvorstand, die studierenden Mitglieder des \\ Verbandes im Studierendenparlament. Das Parlament wurde \\ unter anderem gegründet, um den zahnmedizinischen \\ Nachwuchs für die Berufspolitik zu sensibilisieren und \\ Missstände in der Lehre zu diskutieren. Es vertritt 5.500 \\ studentische Verbandsmitglieder. Bislang konnten 15 von 30 \\ Unistandorten gewonnen werden. Interessierte können sich \\ an Marvin Berchem wenden: mb@fvdz.de. \\ Verschiedene Media-Kanäle sollen in Zukunft Möglichkeiten \\ bieten, die erarbeiteten Inhalte zu veröffentlichen. „Inser
}

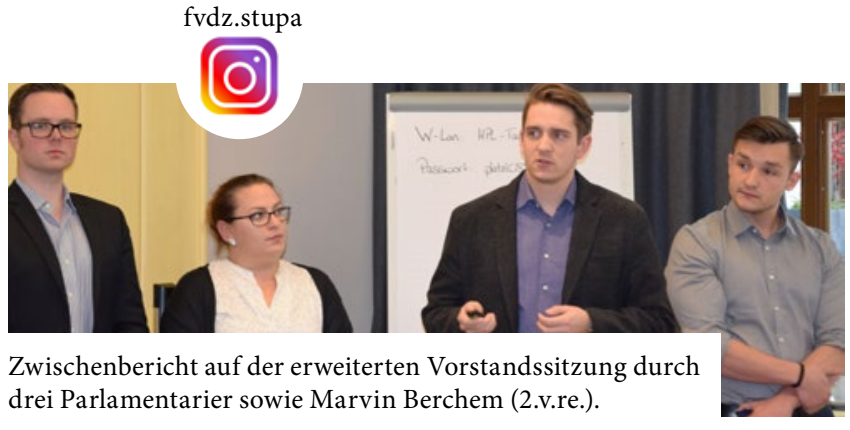

Themenkatalog ist schon jetzt fast so vielfältig wie das Studium selbst, deshalb müssen wir strukturiert arbeiten," sagt Björn Vorpahl, Parlamentarier aus Jena. Die ersten Ergebnisse aus dem Parlament sind in der nächsten Zeit zu erwarten. NEU! Gerne auch bei Instagram folgen.

\section{BAUSTELLE GESUNDHEITSWESEN}

Bürgerversicherung oder duales System-- Als größte Baustelle im Gesundheitswesen wird eine Bürgerversicherung von Experten nicht gerade betrachtet - wohl aber die Zukunftsfähigkeit des deutschen Gesundheitssystems. Dies wurde bei der diesjährigen Health-Jahrestagung des Handelsblattes deutlich. Dort diskutierten Politiker, Beteiligte aus der Gesundheitswirtschaft und Experten darüber, ob das duale Krankenversicherungssystem noch zeitgemäß ist. Dr. Hans Olav Herøy von der HUK-Coburg beispielsweise warf die Frage auf, warum die Gesundheitspolitik nicht

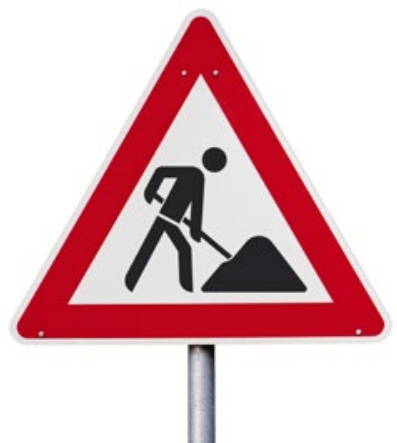

bemüht sei, das, was gut für alle sei, auch für alle einzuführen. Dazu stellte er ein Modell vor, das einen Wechsel von gesetzlicher (GKV) zu privater Krankenkasse (PKV) ebenso möglich macht wie umgekehrt.

Dass sich jedoch genau darüber trefflich streiten lässt, was "gut für alle“ oder gar "gerecht" ist, zeigte die Diskussionsrunde, in der sich Politiker von CDU, SPD, FDP und Linke mit der Frage um ein effizientes Gesundheitssystem auseinandersetzten. SPD-Politiker Thomas Isenberg, Mitglied im Berliner Abgeordnetenhaus, betonte den Stellenwert der Bürgerversicherung in eventuellen Koalitionsverhandlungen als „sozialpolitisches Projekt“, denn die SPD habe bei ihren Wählern „etwas gutzumachen“. Auch der Bundestagsabgeordnete Harald Weinberg (Linke) betonte die Aspekte von Gerechtigkeit und Solidarität, die mit einer Bürgerversicherung „ausbuchstabiert" würden.

Die CDU-Bundestagsabgeordnete und langjährige Gesundheitspolitikerin Karin Maag konterte diese Haltung knapp: Der CDU gehe es nicht um sozialpolitische Projekte, sondern um die Verbesserung von Versorgung. In der Bürgerversicherung sehe sie momentan nur ein Schlagwort - sonst nichts. Eine klare Absage erteilte Maag einer einheitlichen
Gebührenordnung von PKV und GKV. Dass aber die CDU beispielsweise auf dem Rückweg zur paritätischen Beitragsfinanzierung der SPD durchaus entgegenkommen könnte, dementierte sie nicht. Die FDP-Bundestagsabgeordnete und Gesundheitsexpertin Christine Aschenberg-Dugnus machte deutlich, dass derzeit nur Finanzierungsaspekte des Gesundheitssystems diskutiert würden. „Das Thema Gesundheitsversorgung bleibt völlig auf der Strecke", betonte sie.

Einen radikalen Systemwechsel hielt keiner der Politiker auf dem Podium für möglich. Für die CDU liege „die rote Linie“ bei der Dualität, sagte Maag. SAS

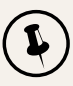

18. - 23. Februar 2018

ISCHGL: FVDZ-Winterkongress

10. März 2018

BONN: Start des FVDZ-

Existenzgründerprogram ms 